Research paper

\title{
Toll-like receptors and cytokines in the brain and in spleen of dogs with visceral leishmaniosis
}

\author{
Fernanda G. Grano ${ }^{\mathrm{a}}$, José Eduardo dos S. Silva ${ }^{\mathrm{a}}$, Guilherme D. Melo ${ }^{\mathrm{b}}$, Milena S. de Souza ${ }^{\mathrm{a}}$, \\ Valéria M.F. Lima ${ }^{a}$, Gisele F. Machado, ${ }^{\mathrm{a}, *}$

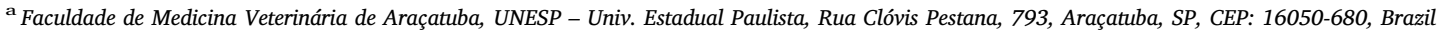 \\ ${ }^{\mathrm{b}}$ Laboratoire des Processus Infectieux à Trypanosomatidés, Département Infection et Epidemiologie, Institut Pasteur, 25-28 Rue du Dr Roux, Paris Cedex 15, 75724, France
}

\section{A R T I C L E I N F O}

\section{Keywords:}

Central nervous system

Gene expression

Leishmania infantum

Neuroinflammation

q-PCR

\begin{abstract}
A B S T R A C T
Visceral leishmaniosis (VL) is a multisystem disease that affects domestic dogs and can have several clinical manifestations, including some rare reports of neurological clinical signs, or it may remain asymptomatic, depending on the individual immune response against the Leishmania parasite. VL involves immune system sensors, such as the Toll-like receptors (TLRs), that are related to innate immunity and inflammation. Previously, we have reported the presence of brain inflammation in infected dogs. Here, we investigated the gene expression profile of TLRs 1-10 in the brain and the spleen of infected dogs, along with the production of proinflammatory cytokines (TNF- $\alpha$, IFN- $\gamma$, IL-1 $\beta$ and IL- 6 ) with the aim of explaining the origin of brain inflammation. The gene expression of TLRs has varied according to the tissue evaluated. In the brain, TLR-4 was only up-regulated in a small subpopulation of infected dogs, while in the spleen, we detected an increase in TLR-5 and TLR-9 transcripts, as well as a reduction in TLRs 2-4 and TLR-10. All cytokines except IL-6 were detected in infected dogs. Moreover, we detected Leishmania DNA in all infected dogs in both tissues evaluated. In the histopathological analysis, we observed a predominance of lymphoplasmacytic infiltrate, mainly in leptomeninges and choroid plexuses, ranging from mild to intense. This study provides the first insight into the TLRs profile in the brain and the spleen during canine VL and provides support to confirm the involvement of sensors of the innate immune system sensors against L. infantum parasites.
\end{abstract}

\section{Introduction}

Visceral leishmaniosis (VL) is an multisystemic disease caused by the Leishmania infantum (L. chagasi) protozoan (Mauricio et al., 2000). Domestic dogs can present with several systemic manifestations (Garcia-Alonso et al., 1996; Ciaramella et al., 1997; Blavier et al., 2001; Reis et al., 2009), including some rare reports of neurological clinical signs (Font et al., 2004; Ikeda et al., 2007; José-lópez et al., 2012; Melo et al., 2012; Gianuzzi et al., 2017), or the infection may remain asymptomatic.

Neurological clinical signs include walking in circles, seizures, paresis, tetraplegia, head tilt, motor incoordination, intention tremor, nystagmus, strabismus and myoclonia (Font et al., 2004; Ikeda et al., 2007; José-lópez et al., 2012; Márquez et al., 2013; Gianuzzi et al., 2017). In addition to neurological clinical signs, brain inflammation has also been reported in dogs with VL, where meningitis and choroiditis are the usual histopathological findings (Nieto et al., 1996; Viñuelas et al., 2001; Melo et al., 2009, 2013, 2015a; Grano et al., 2016; Gianuzzi et al., 2017). Considering these findings, the focus of our research group in recent years has been to investigate the question about why infected dogs present neurological clinical signs and brain inflammation. We have previously suggested two hypotheses. One is that parasite migration from macrophage-rich infected tissues to the brain stimulates inflammation. However, the presence of the Leishmania parasite in the brain is still unclear, although we have detected its DNA in this compartment (Grano et al., 2014; Melo et al., 2015a). The second hypothesis is that peripheral stimuli, such as inflammatory mediators, can reach the central nervous system (CNS), developing local inflammation (Melo et al., 2015a).

Pattern recognition receptors (PRRs) are an important group of innate immune receptors that recognize pathogen-associated molecular patterns (PAMPs), which are conserved structures present in fungi, viruses, bacteria and protozoans (reviewed by Ospelt and Gay, 2010) and recognize damage-associated molecular patterns (DAMPs), which

\footnotetext{
* Corresponding author at: College of Veterinary Medicine, Department of Animal Clinics, Surgery and Reproduction, UNESP - Univ. Estadual Paulista, Rua Clóvis Pestana, 793, Araçatuba, SP, CEP: 16050-680, Brazil.

E-mail address: giselem@fmva.unesp.br (G.F. Machado).
} 
are host-derived proteins (Miyake, 2007; Piccinini and Midwood, 2010) in chronic inflammation, triggering a cascade of immune reactions (Fukata et al., 2009).

TLRs are PRRs that act on the recognition of microbial structures and induce innate and adaptive immune responses (Tuon et al., 2008). Different TLRs detect distinct molecules from viruses, bacteria, fungi and parasites (Kawai and Akira, 2011). Signaling activation through TLRs causes the production of chemokines, inflammatory cytokines, adhesion molecules and co-stimulatory molecules (Ospelt and Gay, 2010). Gene expression of cytokines and chemokines has already been characterized during canine VL in parasite-infected tissues (Panaro et al., 2009; Barbosa et al., 2011; Melo et al., 2015a), as well as in the CNS (Melo et al., 2013; 2015a), where there was an increase in the transcripts of proinflammatory cytokines such as TNF- $\alpha$, IFN- $\gamma$ and IL$1 \beta$ in the brain (Melo et al., 2013).

Concerning TLRs, there are only a few study reports in canine VL. Most studies have focused on TLRs 2, 4 and 9, especially in peripheral blood mononuclear cells (PBMCs) (Melo et al., 2014a), jejunum and colon (Figueiredo et al., 2013), skin (Esteve et al., 2015; Hosein et al., 2015), liver (Hosein et al., 2015), spleen, lymph nodes (Melo et al., 2014b; Hosein et al., 2015) and brain (Melo et al., 2014b).

Studies evaluating the immune response in the CNS of dogs with leishmaniosis are scarce. Despite the growing number of studies about PRRs in recent years, the Toll-like receptor profile in the brain, or even in the spleen, remains to be characterized in order to elucidate which receptors might be related to the recognition of the Leishmania parasite or its antigens in the brain during canine VL. Therefore, the aim of this study was to determine the gene expression of TLR 1-10 and the production of proinflammatory cytokines (TNF- $\alpha$, IFN- $\gamma$, IL-1 $\beta$ and IL-6) in two target compartments of our previous studies: 1) CNS, which is represented here by the brain, the main focus of our studies, and 2) spleen, which is considered an organ bearing the bulk of parasite burden, representing the peripheral system, in which we investigated previously and detected an up-regulation of TLR-2 (Melo et al., 2014b).

\section{Material and methods}

\subsection{Animals}

Twenty-one dogs, 13 males and 8 females, ranging in age from 1 to 4 years old, were selected from the Zoonosis Control Center in the municipality of Araçatuba, São Paulo State, Brazil and included in this study. Seventeen naturally infected dogs by the Leishmania parasite were euthanized with the owner's permission, in compliance with state law (Brasil, 2008), as soon as the VL diagnosis was confirmed. All infected dogs were symptomatic, but they did not present a history of neurological signs. Four uninfected healthy dogs, without underlying conditions or nervous involvement at the time of death, were included in the control group. VL diagnosis was achieved using serology analysis (DPP and ELISA, Bio-Manguinhos/Fiocruz, Manguinhos, RJ, Brazil) and parasitological analysis (popliteal lymph node fine-needle aspiration). All dogs in the study were negative for other infectious agents that can affect the CNS, such as Neospora caninum and Toxoplasma gondii (indirect immunofluorescence = RIFI), and Ehrlichia spp. and Babesia spp. (enzyme-linked immunosorbent assay = ELISA).

\subsection{Sampling}

Dogs were anesthetized with pentobarbital (Hypnol ${ }^{\circ}$ ). Peripheral blood samples were collected in tubes with and without EDTA for hemogram and biochemical analysis, and dogs were euthanized with potassium chloride. Afterwards, we performed necroscopic examinations to evaluate macroscopic alterations and to collect brain and spleen samples. Brains were sagitally sliced and fragments of $0.5 \mathrm{~cm}^{3}$ were pooled from the thalamus, hippocampus, piriform/temporal cortex and periventricular white matter, and $0.5 \mathrm{~cm}^{3}$ fragments of the spleen were stored in RNAlater (AM7020; Applied Biosystems, Austin, TX, USA) and frozen at $-80{ }^{\circ} \mathrm{C}$ or they were directly frozen. The other brain hemisphere was placed in $10 \%$ buffered formalin and paraffin embedded. Fragments were sectioned $(5 \mu \mathrm{m})$ and submitted to hematoxylin and eosin (HE) staining for histopathological analysis.

The brain inflammation was evaluated according to the intensity of the inflammatory infiltrate through the use of a ponderal index divided into four grades (grade 0-3), in accordance with Grano et al. (2016): Grade 0 (no inflammation observed); Grade 1, mild inflammation (slight inflammatory cell infiltrate mainly in the choroid plexuses and leptomeninges); Grade 2, moderate inflammation (moderate inflammatory cell infiltrate mainly in the choroid plexuses, and leptomeninges, along with the presence of some perivascular lymphocytes in the brain tissue); and Grade 3, severe inflammation (remarkable inflammatory cell infiltrate mainly in the choroid plexuses and leptomeninges along with intense perivascular infiltration in the brain tissue).

Regarding the histopatologycal analysis in the spleen, the main objective of this study was more specifically determine the TLR profile in the brain and correlate TLRs with brain inflammation, which we have reported previously. During the project, we decided to compare TLRs from the brain and spleen, as the spleen is one of the most affected organs during the disease, and the spleen is the organ that we have analyzed in other studies (Melo et al., 2014a, b, 2015a). Therefore, we did not collect samples from the spleen for histopathological analysis.

\subsection{Clinical staging}

We determined the serum concentrations of total protein, albumin, urea and creatinine, along with the serum concentrations of antiLeishmania antibodies with indirect ELISA (Lima et al., 2005). The clinical staging of the animals was made according to Solano-Gallego et al. (2011).

\subsection{Leishmania DNA quantification using $q P C R$}

Total DNA extraction was performed from brain and spleen samples with the DNeasy blood \& tissue kit (69504, Qiagen, Hilden, Germany) according to the manufacturer's protocol. DNA was quantified using a NanoDrop spectrophotometer (260/280 ratio between 1.8 and 2.0). qPCRs were performed using the Eppendorf Mastercycler ${ }^{\circ}$ RealPlex ${ }^{2}$, SYBR Green PCR Master Mix (4309155, Applied Biosystems) and $900 \mathrm{nM}$ of each primer (sense: 5'-CCTATTTTACACCAACCCCCAGT-3'; anti-sense: 5'-GGGTAGGGGCGTTCTGCGAAA-3'), which amplify a 116 bp fragment of the minicircle kinetoplast DNA (kDNA) of Leishmania spp. (Ranasinghe et al., 2008), in a total volume of $25 \mu \mathrm{L}$. The amplification conditions were as follows: $94^{\circ} \mathrm{C}$ for $2 \mathrm{~min}$ and 40 cycles of $94^{\circ} \mathrm{C}$ for $15 \mathrm{~s}$ and $60^{\circ} \mathrm{C}$ for $1 \mathrm{~min}$. Then, samples were submitted to a melting curve from $60^{\circ} \mathrm{C}$ to $95^{\circ} \mathrm{C}$; increasing $0.5^{\circ} \mathrm{C}$ every $5 \mathrm{~s}$. The absolute quantification was evaluated using a standard curve with serial dilutions (from $10^{-1}$ to $10^{8}$ promastigotes) of L. infantum DNA.

\subsection{Evaluation of Gene expression by $R T-q P C R$}

Total RNA was extracted from the samples stored in RNAlater using the RNeasy ${ }^{\circ}$ Lipid Tissue Mini Kit (74804, Qiagen) for brain samples and the RNeasy Mini kit (74104, Qiagen) for spleen, according to the manufacturer's protocol. RNA was quantified with a NanoDrop spectrophotometer (260/280 ratio between 2.0 and 2.3) and then submitted to genomic DNA elimination (RNase-Free DNase Set: 79254; Qiagen), and cDNA production was achieved using the $\mathrm{RT}^{2}$ First Strand Kit (330404; Qiagen). Specific canine primers and hydrolysis probes (5'FAM - 3'-BHQ-1) were selected based on the scientific literature (TLR6 , TLR-8 and G3PDH) or gene expression assays were purchased from a commercial source (all the other genes evaluated) (Table 1). qPCR was carried out in a real-time thermocycler (Eppendorf Mastercycler 
Table 1

Primers (forward: F, reverse: R) and hydrolysis probe (P) sequences used for RT-qPCR.

\begin{tabular}{|c|c|c|c|c|c|}
\hline Target & Primers and probes & Sequence $\left(5^{\prime}-3^{\prime}\right)$ & Product size $(\mathrm{pb})$ & GenBank accession number & Reference \\
\hline TLR-1 & & ASSAY ID: Cf03811563_s1 & 100 & NM_001146143.1 & Life Technologies Foster City, CA, USA (4351372) \\
\hline TLR-2 & & ASSAY ID: Cf02625049_s1 & 69 & NM_001005264.3 & Life Technologies Foster City, CA, USA (4351372) \\
\hline TLR-3 & & ASSAY ID: Cf04419557_m1 & 63 & - & Life Technologies Foster City, CA, USA (4331182) \\
\hline TLR-4 & & ASSAY ID: Cf02622203_g1 & 120 & NM_001002950.1 & Life Technologies Foster City, CA, USA (4331182) \\
\hline TLR-5 & & ASSAY ID: Cf04245132_s1 & 100 & NM_001197176.1 & Life Technologies Foster City, CA, USA (4351372) \\
\hline \multirow[t]{3}{*}{ TLR-6 } & $\mathrm{F}$ & TCAAGCATTTAGACCTC̈TCATTCA & 109 & EU551147.1 & Mercier et al. (2012) \\
\hline & $\mathrm{R}$ & CCGTAACTTTGTAGCACTTAAACCT & & & \\
\hline & $\mathrm{P}$ & TGCCCATCTGTAAGGAATTTGGCA & & & \\
\hline TLR-7 & & ASSAY ID: Cf02710573_s1 & 124 & NM_001048124.2 & Life Technologies Foster City, CA, USA (4351372) \\
\hline \multirow[t]{3}{*}{ TLR8 } & $\mathrm{F}$ & TCAGCTACAATGCACACTACTTCC & 138 & XM_005641119.1 & Mercier et al. (2012) \\
\hline & $\mathrm{R}$ & ACGCTTCTCAGGTCTTGCTC & & & \\
\hline & $\mathrm{P}$ & TCCTAGGCGGTGCGTCACCC & & & \\
\hline TLR-9 & & ASSAY ID: Cf02717353_g1 & 136 & NM_001002998.1 & Life Technologies Foster City, CA, USA (4351372) \\
\hline TLR-10 & & ASSAY ID: Cf04181843_s1 & 100 & NM_001173127.1 & Life Technologies Foster City, CA, USA (4351372) \\
\hline RPL32 & - & ASSAY ID: Cf03986518_m1 & & customized assay & Life Technologies Foster City, CA, USA (4351372) \\
\hline \multirow[t]{3}{*}{ G3PDH } & $\mathrm{F}$ & TCAACGGATTTGGCCGTATTGG & 90 & $\mathrm{AB} 022763$ & Peters et al. (2005) \\
\hline & $\mathrm{R}$ & TGAAGGGGTCATTGATGGCG & & & \\
\hline & $\mathrm{P}$ & CAGGGCTGCTTTTAACTCTGGCAAAGTGAA & & & \\
\hline
\end{tabular}

RealPlex $^{2}$ ) using Taqman ${ }^{\bullet}$ Universal Master Mix (4326708, Applied Biosystems). For TLR- 6 and TLR- 8 we used a concentration of $400 \mathrm{nM}$ of each primer and $250 \mathrm{nM}$ of the probe and for G3PDH (glyceraldehyde3-phosphate dehydrogenase) we used $400 \mathrm{nM}$ of each primer and $200 \mathrm{nM}$ of the probe. Each reaction was performed with $5 \mu \mathrm{L}$ of cDNA at a final concentration of $100 \mathrm{ng}$. The amplification conditions were as follows: $50^{\circ} \mathrm{C}$ for $2 \mathrm{~min}, 95^{\circ} \mathrm{C}$ for $10 \mathrm{~min}$ and 45 cycles of $95^{\circ} \mathrm{C}$ for $15 \mathrm{~s}$ and $60^{\circ} \mathrm{C}$ for $1 \mathrm{~min}$. For each target gene, we obtained values of reaction efficiency from amplification of six serial dilutions of a pool of cDNA. Normalization of RT-qPCR data was performed using the reference genes G3PDH and RPL32 (ribosomal protein L32).

\subsection{Cytokine quantification by capture ELISA}

\subsubsection{Brain and spleen extracts}

Extracts were obtained to quantify cytokines by the capture ELISA technique. For this, $60 \mathrm{mg}$ of brain or spleen fragments was added to $1 \mathrm{ml}$ suspensions of complete RPMI-1640 (Sigma, USA), pH 7.2, kept on ice and homogenized in a Tissue Ruptor (Qiagen, Germany) for approximately $5 \mathrm{~min}$. Then, the resulting homogenate was centrifuged at $10,000 \times g$ for $15 \mathrm{~min}$ at $4^{\circ} \mathrm{C}$, and the supernatant was immediately stored at $-80^{\circ} \mathrm{C}$.

\subsubsection{Cytokine quantification}

TNF- $\alpha$, IFN- $\gamma$, IL-1 $\beta$ and IL- 6 concentrations were determined in the brain and spleen supernatants of the dogs of this study by means of capture ELISA using the Duo SET ${ }^{\star}$ Canine TNF- $\alpha$ (Cat. Number: DY1507), Duo SET ${ }^{\circ}$ Canine IFN- $\gamma$ (Cat. Number: 781B), and Duo SET ${ }^{\oplus}$ Canine IL-1 $\beta$ (Cat. Number: DY3747) (R \& D System, Minneapolis, USA) commercial reagents. Procedures were performed in accordance with the manufacturer's instructions. For IL-6, we used an anti-canine monoclonal antibody (mAb) produced in mice (Cat. Number: MAB16091, R \& D System, USA) and biotinynated anti-canine polyclonal antibody produced in goats (Cat. Number: BAF1609, R \& D System, USA). Plates with 96 wells (Corning, USA) were sensitized with $2 \mu \mathrm{g} / \mathrm{ml}$ of $\mathrm{mAb}$ and with $1 \mu \mathrm{g} / \mathrm{ml}$ of detection antibody. Recombinant canine IL-6 (Cat. Number: 1609-CL, R \& D System, USA) was used to generate standard curves. The test was developed with 3,3',5,5'-tetramethylbenzedine - TMB (Sigma, USA). The plates were read using a spectrophotometer (Spectra Count, Packard Bio Science Company, USA) at $450 \mathrm{~nm}$. All samples were measured in duplicate. The detection limit was $1.95 \mathrm{pg} / \mathrm{mL}$ for TNF- $\alpha$ in the brain, $1.95 \mathrm{pg} / \mathrm{mL}$ for TNF- $\alpha$ in the spleen, $62.50 \mathrm{pg} / \mathrm{mL}$ for IFN- $\gamma$ in the brain, $125.00 \mathrm{pg} / \mathrm{mL}$ for IFN- $\gamma$ in the spleen, $0.97 \mathrm{pg} / \mathrm{mL}$ for IL- $1 \beta$ in the brain, $7.81 \mathrm{pg} / \mathrm{mL}$ for IL- $1 \beta$ in the spleen, $39.06 \mathrm{pg} / \mathrm{mL}$ for IL- 6 in the brain, and $78.12 \mathrm{pg} / \mathrm{mL}$ for IL-6 in the spleen.

\subsection{Statistical analysis}

For statistical analysis, all values were log-transformed. For cytokine analysis, we used a four-parameter logistic (4-PL) curve fit. Significant differences between groups were determined by the MannWhitney test or Wilcoxon test for paired samples. Correlations were evaluated with the Spearman correlation coefficient. The Friedman test, followed by the Dunn test, was used to evaluate the intensities of brain inflammation. All analyses were performed using Prism software (Prism 6 , GraphPad). Statistical significance was considered when $\mathrm{P}<0.05$.

\subsection{Ethical issues}

This study was approved by the institutional Ethics and Animal Welfare Committee (CEEA - Comissão de Ética e Experimentação Animal, UNESP, process FOA 00633-2016).

\section{Results}

\subsection{Clinical staging}

We found in the macroscopic examination that $70.58 \%(12 / 17)$ of the infected dogs presented cachexia or weight loss, followed by $64.70 \%(11 / 17)$ with skin disease, including alopecia, nasal hyperkeratosis, ulcers and seborrhea, $35.29 \%$ (6/17) with splenomegaly, $35.29 \%(6 / 17)$ with conjunctivitis and onychogryphosis, and $29.41 \%$ (5/17) with lymphadenopathy.

Concerning the laboratory findings, we observed that $88.23 \%$ (15/ 17) of the infected dogs presented anemia, 52.94\% (9/17) presented lymphocytopenia and $29.41 \%(5 / 17)$ presented thrombocytopenia. All infected dogs presented hypoalbuminemia. Azotemia was evident in $35.29 \%(6 / 17)$ of the infected dogs. All infected dogs presented positive concentrations of serum anti-Leishmania antibodies through ELISA, except two dogs that were serology negative; $17.64 \%$ (3/17) presented low concentrations of antibodies (from cut-off value 0.27 up to 0.4 ), $35.3 \%(6 / 17)$ presented medium concentrations ( 0.4 up to 0.81 ), and $35.3 \%(6 / 17)$ presented high concentrations (over 0.81 ).

Both parasitological examinations in aspirate from lymph nodes aspirates and qPCR were positive in all dogs. Therefore, we classified $29.41 \%(5 / 17)$ of the dogs as stage I, $52.94 \%$ (9/17) as stage II, $11.76 \%$ $(2 / 17)$ as stage III and $5.88 \%(1 / 17)$ of the dogs as the stage IV of the disease. 


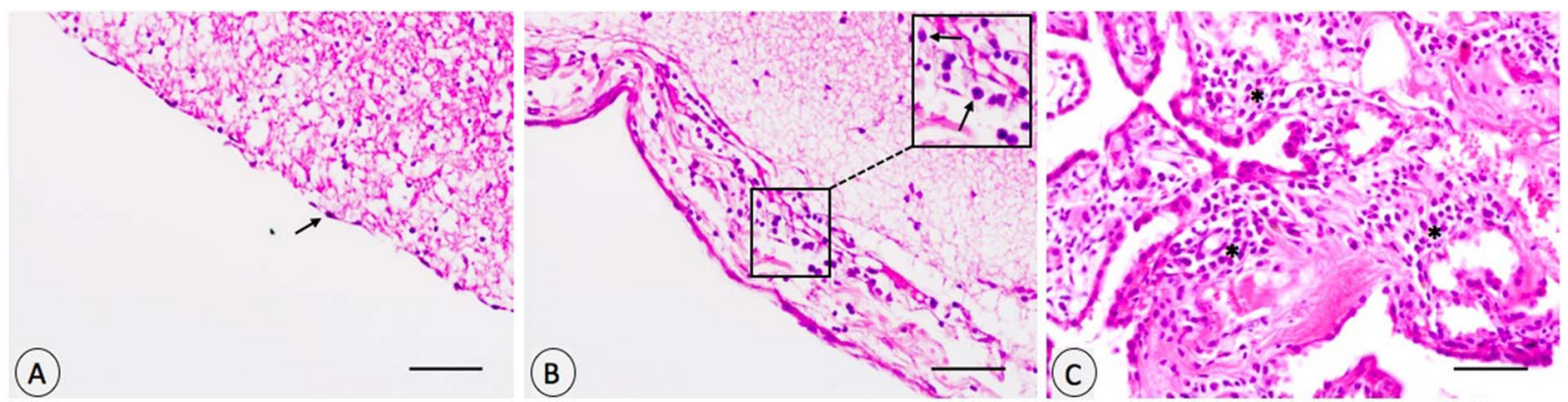

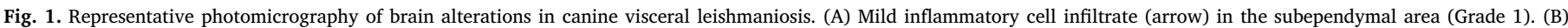

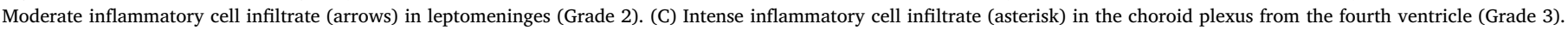
Inset: mononuclear cells enlarged. Hematoxylin and eosin. Scale bar $=50 \mu \mathrm{m}$.

\subsection{Brain histopathological analysis}

Histopathological analysis was performed in the brains of infected and healthy dogs. For the healthy dogs, we detected no brain lesions in the histopathological evaluation. In the infected dogs, we observed mononuclear cell infiltrates, especially composed of lymphocytes and plasma cells in the three brain areas. Leptomeninges and choroid plexuses presented the highest concentration of inflammatory cells when compared with the subependymal area $(P<0.0001)$, ranging from mild to intense inflammation. Fig. 1 shows representative photomicrographs of inflammatory infiltrates in brain areas according to the intensity of inflammation.

In leptomeninges, $21.1 \%$ of the dogs $(n=4)$ presented mild infiltration of inflammatory cells, $36.8 \%(n=7)$ presented moderate inflammatory infiltrate, and $42.1 \%(n=8)$ presented intense inflammatory infiltrate. In the choroid plexuses, $5.3 \%(n=1)$ of the dogs presented no inflammatory infiltrate, $15.8 \%(n=3)$ presented mild intensity, $47.4 \%(n=9)$ showed moderate inflammatory infiltrate and $31.6 \%(\mathrm{n}=6)$ presented intense inflammation. In the subependymal area, $42.1 \%(n=8)$ of the dogs presented with absence of inflammation, $36.8 \%(n=7)$ showed mild inflammatory infiltrate and $21.1 \%$ $(\mathrm{n}=4)$ presented moderate intensity of inflammatory cells (Fig. 2). In the study presented here, we did not detect amastigotes of the Leishmania parasite in the H-E stained brain samples. To evaluate if the intensity of inflammation could vary according to different clinical stages of the disease, we performed a correlation test; however, no correlation was found between these two parameters.

\subsection{Parasite load}

The presence of Leishmania kDNA was detected in all spleen samples from infected dogs. For the brain, Leishmania kDNA was detected in all samples except those from four dogs. The standard curve allowed us to quantify the parasite load in both tissues. Amplification reactions obtained an efficiency value of $95.9 \%$ with a determination coefficient of $\mathrm{r}^{2}=0.998$ and a slope of -3.511 .

The detection range was from 30 to $2,260.000$ parasites/10 mg of spleen and $18(\mathrm{n}=4)$ to 1.380 parasites/10 $\mathrm{mg}$ of brain (Fig. 3). No amplification was observed in the samples used as the negative control for both tissues. The number of parasites in the spleen was significantly higher when compared to the brain $(\mathrm{P}<0.0001)$. However, there was no correlation in the parasite load between both tissues. An absence of correlation was also verified between parasite load and the intensity of brain inflammation.

\subsection{TLR Gene expression in the brain and spleen of infected dogs}

To evaluate the up- or down-regulation of TLR gene expression in the brains and spleens of dogs with VL, we used the $2^{-\Delta \Delta \mathrm{Ct}}$ method according to Livak and Schmittgen (2001) to quantify gene expression using G3PDH and RPL32 as reference genes. The fold change represents by how many times the target gene is more or less expressed in the infected dogs, compared to the control dogs.

In the spleen, we detected an up-regulation of TLR-5 (6.91-fold) and TLR-9 (11.92-fold) in infected dogs, along with a down-regulation of TLR-2 (0.35-fold), TLR-3 (0.23-fold), TLR-4 (0.35-fold) and TLR-10 (0.26-fold). Nevertheless, no correlation between the clinical stage or

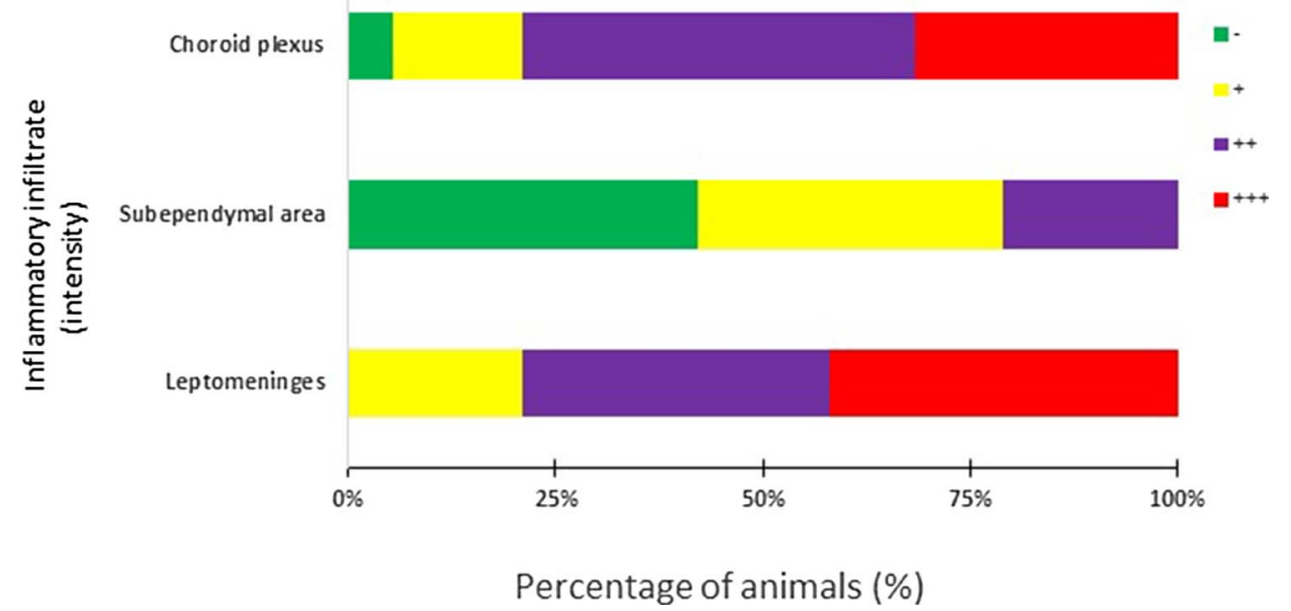

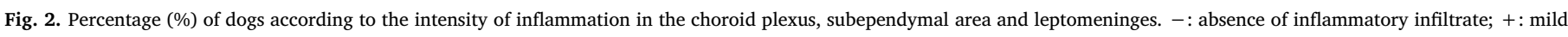
inflammatory infiltrate; ++ : moderate inflammatory infiltrate; +++ : intense inflammatory infiltrate. 


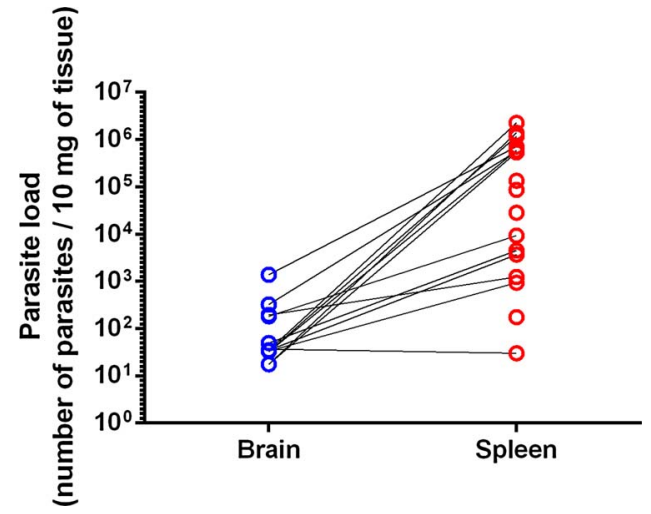

Fig. 3. Individual parasite load determination in the brain and in the spleen of dogs with visceral leishmaniosis. Black lines connect the brain and the spleen values for the same dog.

parasite load and TLRs was observed. For the brain, we did not observe any changes in TLR gene expression (Fig. 4).

As we expected in the distribution of samples from natural infection, we observed important individual variability in all targets evaluated. Nevertheless, different from the other target genes, the distribution of TLR-4 gene expression showed a specific pattern in the brain from infected dogs, with 13 dogs having expression values similar to those of the control dogs and a small subpopulation $(n=4)$ with more evident gene expression. When we evaluated this subpopulation separately, it presented 20.13-fold more TLR-4 expression than the controls (Fig. 5; $P<0.05)$. This subpopulation included dogs at several stages, i.e., stage II $(n=2)$, III $(n=1)$ and IV $(n=1)$. Even in the particular case of these dogs, we detected no correlation among the clinical stages with the parasite load or TLR-4.

\subsection{Cytokine quantification}

All cytokines were detected in infected and healthy dogs in both tissues evaluated (Fig. 6), except for IL-6, which was absent in all dogs. IL-1 $\beta$ was detected at higher concentrations in the spleen from infected dogs, while TNF- $\alpha$ was found at lower levels in the brain of these dogs. For the other proteins, there was no significant difference between the infected and control groups.

Moreover, there was no correlation between the clinical stage or TLR expression and cytokine production for both tissues. The absence of correlation was also verified between the splenic parasite load and the cytokines in the spleen. However, in the brain, there was a moderate negative correlation between the parasite load and IL- $1 \beta(\mathrm{r}=-0.72$; $\mathrm{P}<0.01)$ and TNF- $\alpha(\mathrm{r}=-0.53 ; \mathrm{P}<0.05)$ levels.

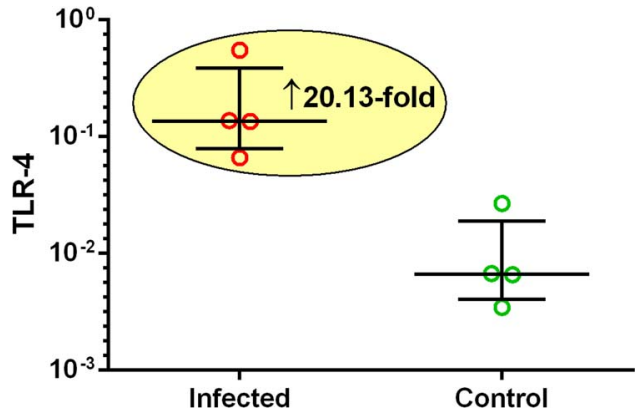

Fig. 5. Individual values of a subpopulation of four infected dogs with remarkable upregulation (20.13-fold more) of TLR-4 gene expression in the brains when compared with the control group. Horizontal lines represent the median and interquartile range values.

\section{Discussion}

We detected brain inflammation, as well as TLR gene expression and Leishmania DNA in the brain and spleens of dogs with VL. The population of dogs evaluated here included animals belonging to the four clinical stages of the classification proposed by Solano-Gallego et al. (2011). However, there was no correlation between the clinical stage or parasite load and TLR expression. An absence of correlation was also observed between the clinical classification and the intensity of brain inflammation. These data indicate that brain inflammation is not related to the clinical staging of infected dogs. Thus, dogs in different clinical stages of the disease can present the same intensity of brain inflammation. Our findings support another study performed with infected dogs presenting neurological clinical signs, which there was absence of correlation between the severity of the animal clinical condition and the intensity of histopathological brain alterations (Ikeda et al., 2007).

Similarly, to previous reports, brain inflammation ranged from mild to intense in the present study (Viñuelas et al., 2001; Márquez et al., 2013; Melo et al., 2013; Grano et al., 2016; Gianuzzi et al., 2017; Oliveira et al., 2017). The presence of lymphocytes and plasma cells observed in the brains from the infected dogs in our study is probably related to blood-brain barrier breakdown (BBB), described previously during canine VL (Melo et al., 2015b), which could allow the entrance of cells and inflammatory mediators to the cerebral parenchyma, contributing to brain inflammation. Observation of neuroinflammation here confirms the brain as an affected organ during canine VL, even in the absence of whole parasite detection in H-E stained sections or of neurological clinical signs. Indeed, there are a limited number of cases reporting the presence of Leishmania in the CNS. The amastigote form of the parasite was previously identified in meninges (Viñuelas et al., 2001) and choroid plexus (Nieto et al., 1996) using H-E staining. In addition, Leishmania was also detected by immunohistochemistry in the

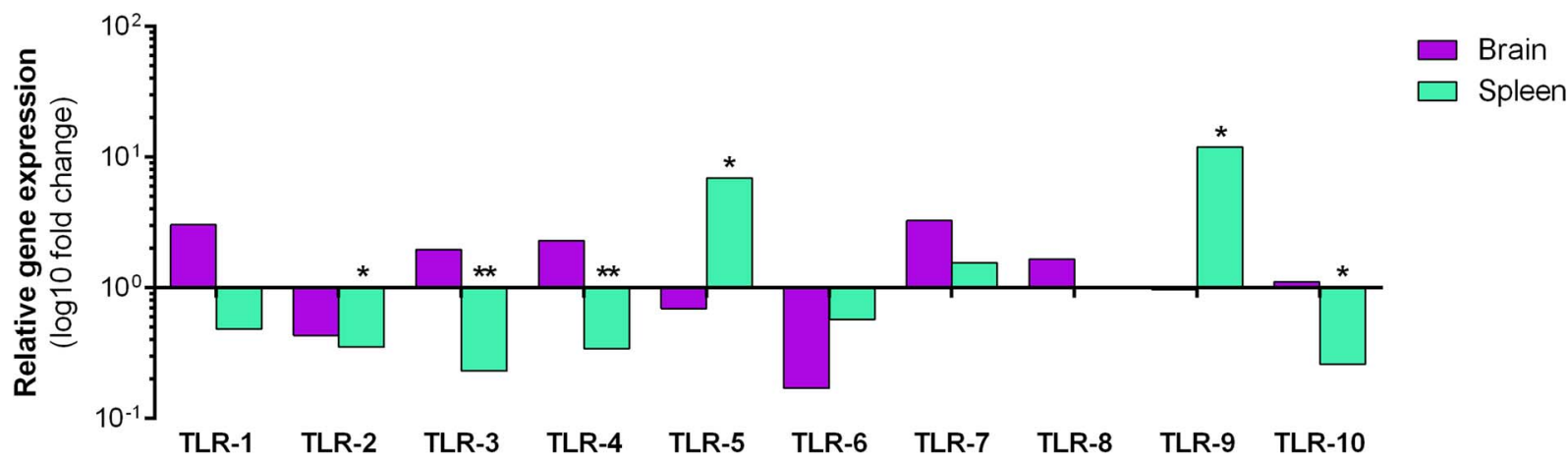

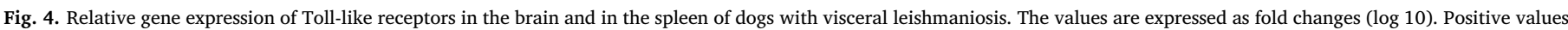

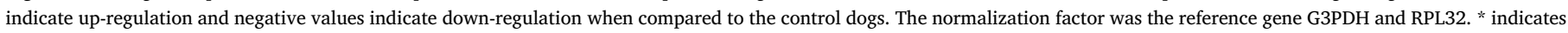
$\mathrm{P}<0.05 ; * *$ indicates $\mathrm{P}<0.01$. 

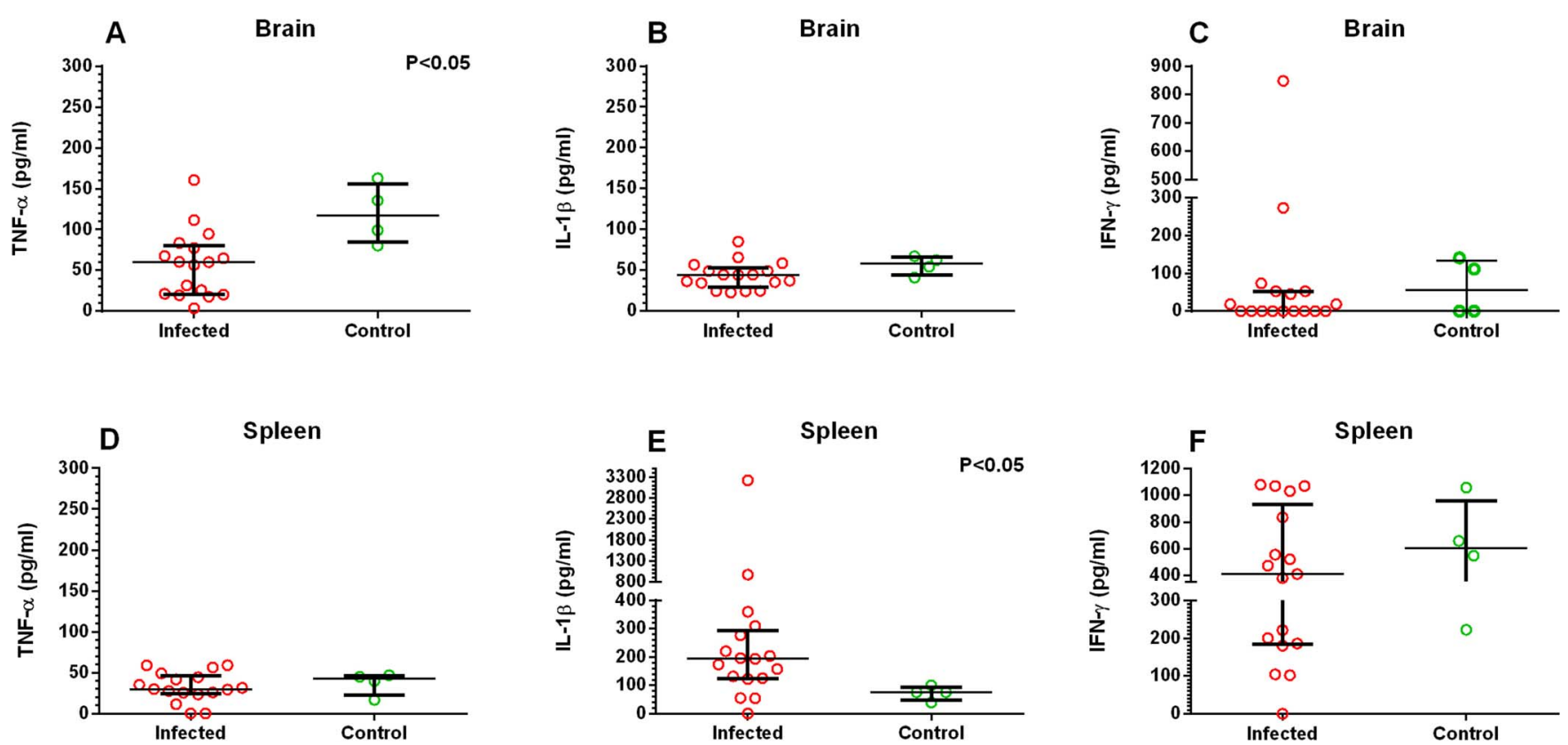

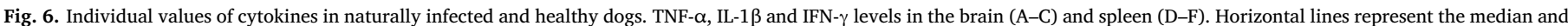
interquartile range values.

CNS (Oliveira et al., 2017), including the spinal cord, brain parenchyma and choroid plexus of one chronically infected dog (Márquez et al., 2013). Although amastigotes were not detected by means of H-E staining, Leishmania DNA was determined in brain samples. Unfortunately, immunohistochemistry was not performed, and this is a limiting factor of this study.

Whole parasites were not detected in the histopathological analysis of the brain, but we detected its DNA. The same was previously verified by our group in other dogs with VL (Melo et al., 2015a; Grano et al., 2016). Perhaps this can be occurring due to the use of a staining technique of low sensitivity. Moreover, the lack of correlation between parasite load and brain inflammation intensity suggests that the development of an inflammatory nervous milieu could occur through other mechanisms and not by direct stimulation by the presence of parasite DNA. One possible mechanism would be the presence of peripheral inflammatory mediators and cells stimulating the CNS. Evidence of blood-cerebrospinal fluid barrier breakdown has been reported during canine $\mathrm{VL}$, in which $\mathrm{T}$ lymphocytes from the blood would somehow stimulate the development of brain inflammation (Grano et al., 2016). Another type of peripheral stimulation in the CNS could be through exosomes. Recently, exosomes were reported to have a role in Leishmania infection. These vesicles can support the transfer of parasite proteins to the cytosol of host cells (Silverman et al., 2010) and appear to contribute to pathogenesis by delivering protein virulence factors to macrophages (Lambertz et al., 2015). In addition, it is also possible that inflammation can originate locally in the brain. The production of inflammatory mediators, such as cytokines and chemokines in the brain, has been reported in dogs with VL (Melo et al., 2013; 2015a), confirming the potential of the brain in the development of a local immune response.

This study provides the first insight into the expression profile of TLR transcripts in the brain, along with the spleen during canine VL. We observed an up-regulation of TLR-9 in the spleens of infected dogs. Activation of TLR-9 occurs by the recognition of microbial DNA and by immune complexes containing DNA (Ospelt and Gay, 2010). An accumulation of immune complexes containing DNA usually can be found in autoimmune diseases (Tian et al., 2007), and the presence of antidouble-stranded DNA antibodies has already been reported previously in human VL (Sakkas et al., 2008; Liberopoulos et al., 2013). In agreement, we have here detected Leishmania DNA in the spleen, which could explain the effect on TLR-9 in this tissue and showing evidence that this immune sensor has a role in detecting the parasite in this tissue. In another study with canine VL, increased frequency of TLR-9 was associated with a lower parasite load in jejunum samples, suggesting the role of TLR-9 in the parasite clearance (Figueiredo et al., 2013). On the other hand, although we detected Leishmania DNA in the brain, TLR-9 gene expression was unchanged in this tissue, which is agreement with our previous results in infected dogs (Melo et al., 2014b). This suggests that the immune response is compartmentalized, and other receptors can be related to immune vigilance in the CNS.

An up-regulation in TLR-5 transcripts was also verified in the spleens from infected dogs. The known ligand for TLR5 is a bacterial flagellin (Singh et al., 2012). Therefore, the role of TLR-5 in directly promoting an immune response against Leishmania parasites or even if it plays roles through its interaction with other TLRs is still unknown and necessitates further investigation.

Regarding TLR-4, only a subpopulation of infected dogs presented up-regulation in the brain compared to the control group. Another detailed study concerning to TLR- 4 would be necessary to evaluate the true role of this receptor in canine VL and its participation in the neuropathogenesis of the disease. In a previous study performed by our research group, we found that TLR-4 transcript was unchanged in the brain and in the spleen, but it was up-regulated in lymph nodes (Melo et al., 2014b), although we detected here down-regulation of the TLR-4 transcript in the spleen. The TLR-4 transcript was also unchanged in the blood during canine VL (Montserrat-Sangrà et al., 2016). The most important known TLR-4 ligand is LPS from gram-negative bacteria (Ospelt and Gay, 2010). Thus, it is unclear which other ligands could be interacting with TLR-4 during VL.

A slightly increased expression of TLR-7 and TLR-8 was observed in the brain and the spleen of dogs with VL, along with TLR-3 in the brain, although this increase was not statistically significant. TLR-3 was reported to contribute to the recognition of the Leishmania parasite (Flandin et al., 2006). This receptor, like TLR-7, TLR-8, and TLR-9, is found inside intracellular endosomal membranes and is able to recognize double-stranded RNA (dsRNA), triggering the NF-KB cascade and IFN- $\gamma$ production (Alexopoulou et al., 2001), while TLR-7 and TLR8 share the same ligand, recognizing single-stranded RNA (ssRNA) from viruses or endogenous sources (Heil et al., 2004). dsRNA is not present in the Leishmania parasite, but many protozoan parasites carry 
endosymbiotic dsRNA viruses (Ogg et al., 2003). Leishmania RNA virus (LRV) exists in several species of Leishmania, including $L$. infantum (Hajjaran et al., 2016), confirming the potential of TLR-3 in having a role in VL. In lymph nodes, the down-regulation of TLR-3 transcripts has been associated with the establishment of disease (Hosein et al., 2015). Moreover, TLR3 was described to be needed for nitric oxide production and parasite phagocytosis (Flandin et al., 2006). Therefore, the lack of TLR-3 observed here in the spleen of infected dogs could be related to susceptibility to Leishmania infection.

A significant reduction in TLR-2 and TLR-10 transcripts was observed in the spleens of infected dogs. Furthermore, a slightly reduced expression of TLR-1 and TLR- 6 was observed in the spleen, along with TLR- 2 and TLR- 6 in the brain, although these reductions were not statistically significant. Therefore, gene expression of transcripts was similarly reduced among TLR-1, TLR-2, TLR- 6 and TLR-10 in the spleen, as well as TLR- 2 and TLR- 6 in the brain. TLR-1 and TLR-10 were slightly elevated in the brain. This can occur because the receptors act synchronously among them. TLRs have been reported to act as dimers in the recognition of PAMPs (Ospelt and Gay, 2010). For example, TLR2 signaling occurs through the formation of heterodimers with TLR-1, TLR-6 or TLR-10 (Takeuchi et al., 2002; Ospelt and Gay, 2010). TLR-1 can signal through dimerization with TLR-2 (Wyllie et al., 2000; Takeuchi et al., 2002), TLR-6 with TLR-1 or TLR-2 (Hornung et al., 2002) and TLR-10 with TLR-1 or TLR-2 (Hasan et al., 2005). Thus, study of the TLR profile is essential because the immune response against Leishmania parasites may involve interactions among multiple receptors.

In our study, TLR-2 transcripts were unchanged in the brains of infected dogs. TLR-2 has already been found unchanged in the brain during canine VL, but an up-regulation of TLR-2 and TLR-9 transcripts was observed particularly in the choroid plexuses from infected dogs (Melo et al., 2014b). Here, we evaluated a pool of samples from several brain areas but not from choroid plexuses. We observed that all TLRs evaluated were unchanged in the brain, except TLR-4, which was elevated in a small subset of animals. Therefore, we suggest the possibility that the choroid plexuses structure is related to the activation of inflammatory pathways related to TLRs in the CNS because it was the structure that presented the most severe inflammation intensity in this study, along with leptomeninges.

We found a reduction in TLR-2 transcripts in the spleens of infected dogs. A reduction in TLR-2 and TLR-4 was previously detected in infected dogs, in macrophages from mononuclear cells and PBMCs, respectively (Melo et al., 2014a). On the other hand, TLR-2 was found to be widely expressed in the spleens of dogs with VL (Melo et al., 2014b). This difference in spleen transcripts can occur due to variability in the individual immune response. In addition, high amounts of TLR-2 and TLR-4 were detected in the spleen during experimental infection with $\mathrm{L}$. chagasi, mainly in the acute phase of the disease, presenting a correlation with high parasitism and high levels of cytokines and nitric oxide (Cezário et al., 2011). In fact, TLR-2 was also up-regulated in the blood of dogs with moderate to severe leishmaniosis at diagnosis but it decreased with clinical improvement during treatment (MontserratSangrà et al., 2016).

In our study, we observed meningitis and choroiditis in infected dogs, showing evidence of blood brain barrier breakdown. IL-1 $\beta$ is the main cytokine involved in BBB breakdown, in addition to TNF- $\alpha$ and IL6 . These cytokines have a role in increasing the expression of adhesion molecules in the endothelium, allowing leukocyte trafficking into the brain (Quagliarello et al., 1991; De Vries et al., 1996; Hickey, 1999; Abbott et al., 2006). The presence of T lymphocytes has already been reported in the CNS of infected dogs (Melo et al., 2009; Grano et al., 2016). Here, IL-1 $\beta$ was detected in similar amounts in the brains of infected and healthy dogs, while IL-6 was not detected in this tissue. These data provide evidence that these cytokines are not related to brain inflammation or active disease.

BBB integrity in dogs with VL can be affected not only by substances that disrupt it but also by a deficiency of structures that support its integrity, such as the tight junctions between the endothelial cells and BBB pericytes (Melo et al., 2013). Pericytes are sensitive to TNF- $\alpha$ and release matrix metalloproteinase 9 (MMP-9), a proteolytic enzyme related to BBB breakdown (Takata et al., 2011). MMP-9 has already been reported in the cerebrospinal fluid as well as in the brains of infected dogs (Machado et al., 2010). We observed more TNF- $\alpha$ in the brains of healthy dogs. Reduced TNF- $\alpha$ production may be due to the action of TNF- $\alpha$ on target cells. Its action occurs through interaction with membrane-bound receptors. After being exposed to TNF- $\alpha$, these cells may reduce their responsiveness to this cytokine by releasing these receptors to the circulation (De Beaux and Fearon et al., 1996), where they can bind to TNF- $\alpha$, making its measurement by ELISA difficult. We have previously reported the brain's potential to produce TNF- $\alpha$ through the detection of an increase in TNF- $\alpha$ transcripts in the brains of infected dogs (Melo et al., 2013). Therefore, we cannot discard TNF$\alpha$ as a substance related to BBB breakdown in dogs with VL.

On the other hand, we detected TNF- $\alpha$ in the spleens of infected dogs; however, it did not differ from control dogs. The lack of a relationship between TNF- $\alpha$ and active disease was previously reported in the sera (Lima et al., 2007). In contrast, TNF- $\alpha$ has been found at higher concentrations in the spleen, liver (De F Michelin et al., 2011) and lymph nodes (Alves et al., 2009; Venturin et al., 2016) from infected dogs compared to healthy dogs.

For IFN- $\gamma$, the levels were similar in the brains and spleens of infected and healthy dogs. In another study, it was verified that decreased intracellular survival of $L$. infantum in canine macrophages is associated with increased production of IFN- $\gamma$ and TNF- $\alpha$, as well as decreased production of IL-10 (Turchetti et al., 2014). Another study supports these findings, where infected dogs lacking $L$. infantum-specific IFN- $\gamma$ production in stimulated whole blood had a high blood parasitemia and severe clinical disease (Solano-Gallego et al., 2016). Therefore, IFN- $\gamma$ seems to have a protective role during canine $\mathrm{VL}$, and the lack of more elevated levels of this cytokine in infected dogs, as observed, can be related to their susceptibility to the disease and brain involvement.

\section{Conclusions}

Our data provide support to explain the involvement of innate immune sensors in the immune response against L. infantum. The data presented herein provide important evidence that TLR-5 and TLR-9 play a role in splenic innate immunity during canine VL and that TLR-4 might be related to the pathogenesis of brain lesions, although the number of brain samples that presented up-regulation of TLR-4 was low, and future investigations should be performed. Concerning cytokines, IFN- $\gamma$ may be related to the resistance to systemic infection and to brain commitment, while TNF- $\alpha$ might be related to BBB breakdown, contributing to brain inflammation. Moreover, we suggest that the brain inflammation observed here might be triggered by other inflammatory pathways, perhaps through other innate immune receptors, in addition to TLRs, or it might originate in another brain area, such as the as choroid plexus.

\section{Conflict of interest statement}

The authors of this work do not have any financial, personal or other relationship with organizations or people that could inadequately influence the content of this paper.

\section{Acknowledgments}

F.G. Grano was supported by a Ph.D.'s degree scholarship from the Fundação de Amparo à Pesquisa do Estado de São Paulo (FAPESP, grant number 2013/25498-1). The research project was supported by FAPESP, grant number 2016/02384-9 and Conselho Nacional de Desenvolvimento Científico e Tecnológico (CNPq), grant number 
420970/2016-9.

\section{References}

Abbott, N.J., Ronnback, L., Hansson, E., 2006. Astrocyte-endothelial interactions at the blood-brain barrier. Nat. Rev. Neurosci. 7 (1), 41-53.

Alexopoulou, L., Holt, A.C., Medzhitov, R., Flavell, R.A., 2001. Recognition of doublestranded RNA and activation of NF-кB by Toll-like receptor 3. Nature 413, 732-738.

Alves, C.F., De Amorim, I.F., Moura, E.P., Ribeiro, R.R., Alves, C.F., Michalick, M.S., Kalapothakis, E., Bruna-Romero, O., Tafuri, W.L., Teixeira, M.M., Melo, M.N., 2009. Expression of IFN-gamma, TNF-alpha, IL-10 and TGF-beta in lymph nodes associates with parasite load and clinical form of disease in dogs naturally infected with Leishmania (Leishmania) chagasi. Vet. Immunol. Immunopathol. 128, 349-358.

Barbosa, M.A.G., Alexandre-Pires, G., Soares-Clemente, M., Marques, C., Roos Rodrigues, O., Villa de Brito, T., Pereira da Fonseca, I., Alves, L.C., Santos-Gomes, G.M., 2011. Cytokine gene expression in the tissues of dogs infected by Leishmania infantum. J. Comp. Pathol. 145, 336-344.

Blavier, A., Keroack, S., Denerolle, P., Goy-Thollot, I., Chabanne, L., Cadore, J.L., Bourdoiseau, G., 2001. Atypical forms of canine leishmaniosis. Vet. J. 162, 108-120.

Brasil. Ministério da Saúde, 2008. Portaria interministerial $n^{\circ} 1.426$. de 11 de julho de 2008.

Cezário, G.A.G., Oliveira, L.R.C., Peresi, E., Nicolete, V.C., Polettini, J., De Lima, C.R., Gatto, M., Calvi, S.A., 2011. Analysis of the expression of Toll-like receptors 2 and 4 and cytokine production during experimental Leishmania chagasi infection. Mem. Inst. Oswaldo Cruz 106, 573-583.

Ciaramella, P., Oliva, G., De Luna, R., Ambrosio, R., Cortese, L., Persechino, A., Gradoni, L., Scalone, A., 1997. A retrospective clinical study of canine leishmaniasis in 150 dogs naturally infected by Leishmania infantum. Vet. Rec. 141, 539-543.

De Beaux, A.C., Fearon, K.C., 1996. Circulating endotoxin, tumour necrosis factor-alpha, and their natural antagonists in the pathophysiology of acute pancreatitis. Scand. J. Gastroenterol. Suppl. 219, 43-47.

De F Michelin, A., Perri, S.H., De Lima, V.M., 2011. Evaluation of TNF- $\alpha$, IL-4, and IL-10 and parasite density in spleen and liver of $L$. (L.) chagasi naturally infected dogs, 2011. Ann. Trop. Med. Parasitol. 105, 373-383.

De Vries, H.E., Blom-Roosemalen, M.C.M., Oosten, M.V., De Boer, A.G., Van Berkel, T.J.C., Breimer, D.D., Kuiper, J., 1996. The influence of cytokines on the integrity of the blood-brain barrier in vitro. J. Neuroimmunol. 64 (1), 37-43.

Esteve, L.O., Saz, S.V., Hosein, S., Solano-Gallego, L., 2015. Histopathological findings and detection of toll-like receptor2 in cutaneous lesions of canine leishmaniosis. Vet. Parasitol. 209, 157-163.

Figueiredo, M.M., Amorim, I.F.G., Pinto, A.J.W., Barbosa, V.S., Pinheiro, L.J., Deoti, B., Faria, A.M.C., Tafuri, W.L., 2013. Expression of Toll-like receptors 2 and 9 in cells of dog jejunum and colon naturally infected with Leishmania infantum. BMC Immunol. $14,22$.

Flandin, J.F., Chano, F., Descoteaux, A., 2006. RNA interference reveals a role for TLR2 and TLR3 in the recognition of Leishmania donovani promastigotes by interferongamma-primed macrophages. Eur. J. Immunol. 36, 411-420.

Font, A., Mascort, J., Altimira, J., Closa, J.M., Vilafranca, M., 2004. Acute paraplegia associated with vasculitis in a dog with leishmaniasis. J. Small Anim. Pract. 45, 199-201.

Fukata, M., Vamadevan, A.S., Abreu, M.T., 2009. Toll-like receptors (TLRs) and Nod-like receptors (NLRs) in inflammatory disorders. Semin. Immunol. 21, 242-253.

Garcia-Alonso, M., Nieto, A.G., Blanco, A., Requena, J.M., Alonso, C., Navarrete, I., 1996. Presence of antibodies in the aqueous humour and cerebrospinal fluid during Leishmania infections in dogs. Pathological features at the central nervous system. Parasite Immunol. 18, 539-546.

Gianuzzi, A.P., Ricciardi, M., De Simone, A., Gernone, F., 2017. Neurological manifestations in dogs naturally infected by Leishmania infantum: descriptions of 10 cases and a review of the literature. J. Small Anim. Pract. 58, 125-138.

Grano, F.G., Melo, G.D., Belinchón-Lorenzo, S., Gómez-Nieto, L.C., Machado, G.F., 2014. First detection of Leishmania infantum DNA within the brain of naturally infected dogs. Vet. Parasitol. 204, 376-380.

Grano, F.G., Silva, J.E.S., Melo, G.D., Perosso, J., Lima, V.M.F., Machado, G.F., 2016. T lymphocyte immunophenotypes in the cerebrospinal fluid of dogs with visceral leishmaniasis. Vet. Parasitol. 232, 12-20.

Hajjaran, H., Mahdi, M., Mohebali, M., Samimi-Rad, K., Ataei-Pirkooh, A., Kazemi-Rad, E., Naddaf, S.R., Raoofian, R., 2016. Detection and molecular identification of Leishmania RNA virus (LRV) in Iranian Leishmania species. Arch. Virol. 161 (12), 3385-3390.

Hasan, U., Chaffois, C., Gaillard, C., Saulnier, V., Merck, E., Tancredi, S., Guiet, S., Brière, F., Vlach, J., Lebecque, S., Trinchieri, G., Bates, E.E.M., 2005. Human TLR10 is a functional receptor, expressed by B cells and plasmacytoid dendritic cells, which activates gene transcription through MyD88. J. Immunol. 174 (5), 2942-2950.

Heil, F., Hemmi, H., Hochrein, H., Ampenberger, F., Kirschning, C., Akira, S., Lipford, G., Wagner, H., Bauer, S., 2004. Species specific recognition of single-stranded RNA via toll-like receptor 7 and 8. Science 303 (5663), 1526-1529.

Hickey, W.F., 1999. Leukocyte traffic in the central nervous system: the participants and their roles. Semin. Immunol. 11 (2), 125-137.

Hornung, V., Rothenfusser, S., Britsch, S., Krug, A., Jahrsdorfer, B., Giese, T., Endres, S., Hartmann, G., 2002. Quantitative expression of toll-like receptor 1-10 mRNA in cellular subsets of human peripheral blood mononuclear cells and sensitivity to CpG oligodeoxynucleotides. J. Immunol. 168 (9), 4531-4537.

Hosein, S., Rodríguez-Cortés, A., Blake, D.P., Allenspach, K., Alberola, J., Solano-Gallego, L., 2015. Transcription of Toll-like receptors 2, 3, 4 and 9, FoxP3 and Th17 cytokines in a susceptible experimental model of canine Leishmania infantum infection. PLos
One 10 (10), e0140325.

Ikeda, F.A., Laurenti, M.D., Corbett, C.E., Feitosa, M.M., Machado, G.F., Perry, S.H.V., 2007. Histological and immunohistochemical study of the central nervous system of dogs naturally infected by Leishmania (Leishmania) chagasi. Braz. J. Vet. Res. Anim. Sci. 44, 5-11.

José-López, R., De la Fuente, C., Añor, S., 2012. Presumed brain infarctions in two dogs with systemic leishmaniasis. J. Small Anim. Pract. 53, 554-557.

Kawai, T., Akira, S., 2011. Toll-like receptors and their crosstalk with other innate receptors in infection and immunity. Immunity 34 (5), 637-650.

Lambertz, U., Ovando, M.E.O., Vasconcelos, E.Jr., Unrau, P.J., Myler, P.J., 2015. Small RNAs derived from tRNAs and rRNAs are highly enriched in exosomes from both old and new world Leishmania providing evidence for conserved exosomal RNA packaging. BMC Genomics 16, 151.

Liberopoulos, E., Kei, A., Apostolou, F., Elisaf, M., 2013. Autoimmune manifestations in patients with visceral leishmaniasis. J. Microbiol. Immunol. Infect. 46, 302-305.

Lima, V.M.F., Biazzono, L., Silva, A.C., Correa, A.P.F.L., Luvizotto, M.C.R., 2005. Serological diagnosis of visceral leishmaniasis by an enzyme immunoassay using protein A in naturally infected dogs. Braz. J. Vet. Res. Anim. Sci. 25 (4), 215-218.

Lima, V.M.F., Peiro, J.R., Vasconcelos, R.O., 2007. IL-6 and TNF-a production during active canine visceral leishmaniasis. Vet. Immunol. Immunopathol. 115, 189-193.

Livak, K.J., Schmittgen, T.D., 2001. Analysis of relative gene expression data using realtime quantitative PCR and the 2- $\Delta \Delta$ Ct method. Methods 25, 402-408.

Machado, G.F., Melo, G.D., Moraes, O.C., Souza, M.S., Marcondes, M., Perri, S.H.V., Vasconcelos, R.O., 2010. Differential alterations in the activity of matrix metalloproteinases within the nervous tissue of dogs in distinct manifestations of visceral leishmaniasis. Vet. Immunol. Immunopathol. 136, 340-345.

Márquez, M., Pedregosa, J.R., López, J., Marco-Salazar, P., Fondevila, D., Pumarola, M., 2013. Leishmania amastigotes in the central nervous system of a naturally infected dog. J. Vet. Diagn. Invest. 25 (1), 142-146.

Mauricio, I.L., Stothard, J.R., Miles, M.A., 2000. The strange case of Leishmania chagasi. Parasitol. Today 16, 188-189.

Melo, G.D., MarcondeS, M., Vasconcelos, R.O., Machado, G.F., 2009. Leukocyte entry into the CNS of Leishmania chagasi naturally infected dogs. Vet. Parasitol. 162, 248-256.

Melo, G.D., Marcondes, M., Machado, G.F., 2012. Canine cerebral leishmaniasis: potential role of matrix metalloproteinase- 2 in the development of neurological disease. Vet. Immunol. Immunopathol. 148, 260-266.

Melo, G.D., Seraguci, T.F., Schweigert, A., Silva, J.E.S., Grano, F.G., Peiró, J.R., Lima, V.M.F., Machado, G.F., 2013. Pro-inflammatory cytokines predominate in the brains of dogs with visceral leishmaniasis: a natural model of neuroinflammation during systemic parasitic infection. Vet. Parasitol. 192, 57-66.

Melo, L.M., Perosso, J., Almeida, B.F.M., Silva, K.L.O., Somenzari, M.A., Lima, V.M.F., 2014a. Effects of P-MAPA immunomodulator on Toll-like receptor 2, ROS, nitric oxide, MAPKp38 and IKK in PBMC and macrophages from dogs with visceral leishmaniasis. Int. Immunopharmacol. 18, 373-378.

Melo, G.D., Silva, J.E.S., Grano, F.G., Homem, C.G., Machado, G.F., 2014b. Compartmentalized gene expression of toll-like receptors 2, 4 and 9 in the brain and peripheral lymphoid organs during canine visceral leishmaniasis. Parasite Immunol. 36, 726-731.

Melo, G.D., Silva, J.E.S., Grano, F.G., Souza, M.S., Machado, G.F., 2015a. Leishmania infection and neuroinflammation: specific chemokine profile and absence of parasites in the brain of naturally-infected dogs. J. Neuroimmunol. 289, 21-29.

Melo, G.D., Grano, F.G., Silva, J.E.S., Kremer, B.E., Lima, V.M.F., Machado, G.F., 2015b. Blood-brain barrier disruption during spontaneous canine visceral leishmaniasis. Parasite Immunol. 37 (12), 635-645.

Mercier, I.R., Peters, M.J., Day, C., Day, M.J., Clercx, C., Peeters, D., 2012. Toll- and NODlike receptor mRNA expression incanine sino-nasal aspergillosis and idiopathic lymphoplasmacytic rhinitis. Vet. Immunol. Immunopathol. 145, 618-624.

Miyake, K., 2007. Innate immune sensing of pathogens and danger signals by cell surface Toll-like receptors. Semin. Immunol. 19, 3-10.

Montserrat-Sangrà, S., Alborch, L., Ordeix, L., Solano-Gallego, L., 2016. TLR-2 and TLR-4 transcriptions in unstimulated blood from dogs with leishmaniosis due to Leishmania infantum at the time of diagnosis and during follow-up treatment. Vet. Parasitol. 228, 172-179.

Nieto, C.G., Viñuelas, J., Blanco, A., Garcia-Alonso, M., Verdugo, S.G., Navarrete, I., 1996. Detection of Leishmania infantum amastigotes in canine choroid plexus. Vet. Rec. 139, 346-347.

Ogg, M.M., Carrion, R.Jr., Botelho, A.C., Mayrink, W., Correa-Oliveira, R., Patterson, J.L., 2003. Short report: quantification of leishmaniavirus RNA in clinical samples and its possible role in pathogenesis. Am. J. Trop. Med. Hyg. 69, 309-313.

Oliveira, V.D.C., Boechat, V.C., Mendes Junior, A.A.V., Madeira, M.F., Ferreira, L.C., Figueiredo, F.B., Campos, M.P., De Carvalho Rodrigues, F.D.C., Carvalhaes de Oliveira, R.V., Amendoeira, M.R.R., Menezes, R.C., 2017. Occurrence of Leishmania infantum in the central nervous system of naturally infected dogs: parasite load, viability, co-infections and histological alterations. PLoS One 12 (4), e0175588.

Ospelt, C., Gay, S., 2010. TLRs and chronic inflammation. Int. J. Biochem. Cell Biol. 42, $495-505$.

Panaro, M.A., Brandonisio, O., Cianciulli, A., Cavallo, P., Lacasella, V., Paradies, P., Testini, G., De Caprariis, D., Mitolo, V., Otranto, D., 2009. Cytokine expression in dogs with natural Leishmania infantum infection. Parasitology 136, 823-831.

Peters, I.R., Helps, C.R., Calvert, E.L., Hall, E.J., Day, M.J., 2005. Cytokine mRNA quantification in histologically normal canine duodenal mucosa by real-time RT-PCR. Vet. Immunol. Immunopathol. 103, 101-111.

Piccinini, A.M., Midwood, K.S., 2010. DAMPening inflammation by modulating TLR signalling. Mediat. Inflamm. 2010.

Quagliarello, V.J., Wispelwey, B., Long, W.J., Scheld, W.M., 1991. Recombinant human interleukin-1 induces meningitis and blood-brain barrier injury in the rat. 
Characterization and comparison with tumor necrosis factor. J. Clin. Invest. 87 (4), 1360-1366.

Ranasinghe, S., Rogers, M.E., Hamilton, J.G.C., Bates, P.A., Maingon, R.D.C., 2008. A realtime PCR assay to estimate Leishmania chagasi load in its natural sand fly vector Lutzomyia longipalpis. Trans. R. Soc. Trop. Med. Hyg. 102 (9), 875-882.

Reis, A.B., Martins-Filho, O.A., Teixeira-Carvalho, A., Giunchetti, R.C., Carneiro, C.M., Mayrink, W., Tafuri, W.L., Corrêa-Oliveira, R., 2009. Systemic and compartmentalized immune response in canine visceral leishmaniasis. Vet. Immunol. Immunopathol. 128, 87-95.

Sakkas, L.I., Boulbou, M., Kyriakou, D., Makri, I., Sinani, C., Germenis, A., Stathakis, N., 2008. Immunological features of visceral leishmaniasis may mimic systemic lupus erythematosus. Clin. Biochem. 41, 65-68.

Silverman, J.M., Clos, J., De'Oliveira, C.C., Shirvani, O., Fang, Y., Wang, C., Foster, L.J., Reiner, N.E., 2010. An exosome-based secretion pathway is responsible for protein export from Leishmania and communication with macrophages. J. Cell Sci. 123, 842-852.

Singh, R.K., Srivastava, A., Singh, N., 2012. Toll-like receptor signaling: a perspective to develop vaccine against leishmaniasis. Microbiol. Res. 167 (8), 445-451.

Solano-Gallego, L., Miro, G., Koutinas, A., Cardoso, L., Pennisi, M.G., Ferrer, L., Bourdeau, P., Oliva, G., Baneth, G., 2011. LeishVet guidelines for the practical management of canine leishmaniosis. Parasites Vectors 4 (1), 86.

Solano-Gallego, L., Montserrat-Sangrà, S., Ordeix, L., Martínez-Orellana, P., 2016. Leishmania infantum-specific production of IFN- $\gamma$ and IL-10 in stimulated blood from dogs with clinical leishmaniosis. Parasites Vectors 9, 317.

Takata, F., Dohgu, S., Matsumoto, J., Takahashi, H., Machida, T., Wakigawa, T., Harada, E., Miyaji, H., Koga, M., Nishioku, T., Yamauchi, A., Kataoka, Y., 2011. Brain pericytes among cells constituting the blood-brain barrier are highly sensitive to tumor necrosis factor-alpha, releasing matrix metalloproteinase-9 and migrating in vitro. J. Neuroinflamm. 8 (1), 106.

Takeuchi, O., Sato, S., Horiuchi, T., Hoshino, K., Takeda, K., Dong, Z., Modlin, R.L., Akira, S., 2002. Cutting edge: role of Toll-like receptor 1 in mediating immune response to microbial lipoproteins. J. Immunol. 169 (1), 10-14.

Tian, J., Avalos, A.M., Mao, S., Chen, B., Senthil, K., Wu, H., Parroche, P., Drabic, S., Golenbock, D., Sirois, C., Hua, J., An, L.L., Audoly, L., La Rosa, G., Bierhaus, A., Naworth, P., Marshak-Rothstein, A., Crow, M.K., Fitzgerals, K.A., Latz, E., Kiener, P.A., Coyle, A.J., 2007. Toll-like receptor 9-dependent activation by DNA containing immune complexes is mediated by HMGB1 and RAGE. Nat. Immunol. 8, 487-496.

Tuon, F.F., Amato, V.S., Bacha, H.A., Almusawi, T., Duarte, M.I., Neto, V.A., 2008. Tolllike receptors and leishmaniasis. Infect. Immun. 76, 866-872.

Turchetti, A.P., Costa, L.F., Romão, E.L., Fujiwara, R.T., Paixão, T.A., Santos, R.L., 2014. Transcription of innate immunity genes and cytokine secretion by canine macrophages resistant or susceptible to intracellular survival of Leishmania infantum. Vet. Immunol. Immunopathol. 163, 67-76.

Venturin, G.L., Chiku, V.M., Silva, K.L.O., Almeida, B.F.M., de, Lima, V.M.F., 2016. M1 polarization and the effect of PGE2 on TNF- $\alpha$ production by lymph no de cells from dogs with visceral leishmaniasis. Parasite Immunol. 38, 698-704.

Viñuelas, J., Garcia-Alonso, M., Ferrando, L., Navarrete, I., Molano, I., Mirón, C., Carcelén, J., Alonso, C., Nieto, C.G., 2001. Meningeal leishmaniosis induced by Leishmania infantum in naturally infected dogs. Vet. Parasitol. 101, 23-27.

Wyllie, D.H., Kiss-Toth, E., Visintin, A., Smith, S.C., Boussouf, S., Segal, D.M., Duff, G.W., Dower, S.K., 2000. Evidence for an accessory protein function for Toll-like receptor 1 in anti-bacterial responses. J. Immunol. 165 (12), 7125-7132. 